\title{
O DIREITO ADMINISTRATIVO NA FACULDADE DE DIREITO DE SÃO PAULO: ANÁliSE PARATEXTUAL DE MANUAIS NO PERÍODO DE 1889-1940 ${ }^{1}$
}

\author{
ADMINISTRATIVE LAW IN SAO PAULO LAW SCHOOL: PARATEXT ANALYSIS OF \\ HANDBOOKS DATING FROM 1889 TO 1940
}

Igor Tostes Fiorezzi*

\begin{abstract}
Resumo:
$\mathrm{O}$ artigo investiga a teoria do direito administrativo em formação na Faculdade de Direito de São Paulo durante o período de 1889-1940. O objetivo é verificar ou não a ocorrência da hipótese de que, nesse período, a teoria administrativista se voltou à elaboração de obras destinadas principalmente aos estudantes, cujos temas principais versavam sobre a organização e a ação administrativas. Empreende-se a análise partir do estudo de manuais produzidos por professores (substitutos, catedráticos e extraordinários), que ministraram a disciplina de Direito Administrativo na instituição nesse recorte temporal. A metodologia se volta ao estudo de três tipos de paratextos existentes nesses manuais: o prefácio, os intertítulos e as notas ou citações.

Palavras-chave: História do Direito. Direito Administrativo. Faculdade de Direito de São Paulo. Cultura Jurídica. Paratextos. Professores. Prefácio.
\end{abstract}

\begin{abstract}
:
The paper investigates the Administrative Law doctrine in formation at the Sao Paulo Law School between 1889-1940. The objective is to verify the hypothesis whether or not, in this period, the administrative law theory emphasized the writing of handbooks mainly used by students; and whether or not the main subjects were related to Public Administration's organisation and action. The analysis is carried out based on the study of substitute, full and extraordinary professors' handbooks, who taught Administrative Law at this institution in that time. The methodology concerns the analysis of three paratextual elements in these handbooks: preface, intertitles and notes or quotes.
\end{abstract}

Keywords: Legal History. Administrative Law. Sao Paulo Law School. Legal Culture. Paratext. Professors. Preface.

1 Esse artigo é resultante de PIBIC-USP 2018, orientado pelo Professor Doutor Samuel Rodrigues Barbosa.

* Graduando da Faculdade de Direito da Universidade de São Paulo com dupla titulação pela Université Jean Moulin Lyon 3 (Programa PITES). E-mail: igor.fiorezzi@usp.br. 
1. Introdução

O presente artigo pretende investigar a teoria produzida pelos professores da Faculdade de Direito de São Paulo sobre o direito administrativo durante o período da Primeira República do Brasil.

A Cadeira de Direito Administrativo nas faculdades de direito brasileiras remonta ao ano de 1851, período em que o Decreto n. 608 autoriza a sua criação. A sua criação efetiva vem a acontecer em 1853, com Decreto n. 1.134. Entretanto, o ensino da disciplina só se deu para os alunos do $5^{\circ}$ ano de 1855 (BARROS JÚNIOR, 1974).

Depois disso, a Cadeira passa por uma série de mudanças, entre as quais se destacam a Reforma Benjamin Constant de 1891 e a Rivadávia Corrêa de 1911.

Adota-se, neste artigo, o termo "Direito Administrativo", para fazer referência às disciplinas de: Direito Administrativo antes da Reforma Benjamin Constant, Ciência da administração e direito administrativo do curso de Ciências Sociais, Noções de economia política e direito administrativo do curso de Ciências Jurídicas, Explicação sucinta do direito pátrio constitucional e administrativo do curso de Notariado, Ciência da Administração e Direito Administrativo nos primeiros anos posteriores à reforma e, finalmente, Direito administrativo e ciência da administração, nomenclatura consolidada em 1929. Deixa-se o termo em minúsculas "direito administrativo" para fazer referência genérica ao ramo do direito.

As fontes históricas do período de 1855 a 1932 (FREITAS, 1906, 1907; BUENO, 1908, 1909, 1910, 1911; ALMEIDA JUNIOR; MAIA; CASTILHOS, 1912; FREITAS, 1914-1925a, 1914-1925b, 1914-1925c, 1914-1925d, 1914-1925e, 1914-1925f, 1914-1925g, 1914-1925h, 1914-1925i, 1914-1925j; CARVALHO, 1914-1925a, 19141925b; FERRAZ, 1927, 1828, 1929; MACHADO, 1932) informam que as disciplinas listadas acima foram lecionadas por diversos professores, tanto substitutos, quanto catedráticos e extraordinários. Foram eles: José Ignácio Silveira da Motta, Antônio Joaquim Ribas, Francisco Maria de Souza Furtado de Mendonça, Américo Brasiliense, José Rubino de Oliveira, Manoel Clementino de Oliveira Escorel, Manoel Pedro Villaboim, João Pedro da Veiga Filho, Jesuíno Ubaldo Cardoso de Melo, José Machado de Oliveira, Dario Sebastião de Oliveira Ribeiro, João Mendes de Almeida Júnior, Ernesto Moura, Raphael Corrêa de Sampaio, Manoel Aureliano de Gusmão, Manoel Pacheco Prates, José Joaquim Cardozo de Mello Netto, Spencer Vampré, Teophilo Benedito de Souza Carvalho e Mario Masagão.

Após essa contextualização, passa-se propriamente às considerações sobre teoria do direito administrativo no Brasil.

Guandalini Junior (2011), ao investigar o discurso jurídico-científico sobre o direito administrativo, descreve a sua evolução em quatro fases. A primeira fase, 
anterior a 1854, trata de um período em que as formulações de direito administrativo se concentravam no Conselho de Estado. A segunda fase, de 1854 a 1879, é a de formação desse direito, na intenção de dar legitimidade ao novo Estado. Uma terceira fase, de 1879 a 1891, é descrita como a consolidação da estrutura administrativa brasileira. Por fim, esboça-se uma quarta fase, a partir de 1891, em que o direito administrativo passa a ter como função principal não mais a atribuição de legitimidade ao Estado, mas sim a de disciplinar a vida social dos indivíduos.

No mesmo sentido, Menezes de Almeida (2015, p. 436), ao investigar a teoria do direito administrativo, no Brasil, atribui sua formação aos períodos do Império e da Primeira República. Durante esses períodos, a teoria administrativista brasileira não atinge a "densidade suficiente para que se estabeleçam padrões a serem transmitidos consistentemente entre as gerações de administrativistas". Somente em fins da década de 1940 se identifica um primeiro estágio evolutivo dessa teoria, "com massa crítica suficiente para gerar uma continuidade teórica, ou seja, com a definição de certos padrões transmitidos no tempo" (ALMEIDA, 2015, p. 436).

O objetivo principal desse artigo é analisar como era parte da teoria do direito administrativo produzida no Brasil. A parte que aqui é objeto se refere à teoria do direito administrativo presente no ensino dessa disciplina por professores da Faculdade de Direito de São Paulo no período que vai de 1889 a 1940. Essa escolha cronológica reflete a mudança de forma estatal ocorrida com a Proclamação da República e se estende até fins dos anos 1930, para incluir também parte do primeiro estágio evolutivo da formação da teoria do direito administrativo demonstrada acima.

As investigações recaem sobre a teoria, ainda que apenas de uma pequena e restrita parte dela, e não da doutrina. A diferença entre teoria e doutrina reside no fato de que a doutrina exerce, em alguma medida, uma função de autoridade sobre o modo de ser do direito vigente, expressando uma certa opinião pessoal. A teoria, por outro lado, não apresenta essas características, "sendo eminentemente opinativa”, comportando "o pensamento individualizado de algum ou de alguns autores" (ALMEIDA, 2015, p. 70).

No ambiente universitário, a teoria se faz presente no âmbito do ensino, da pesquisa e da extensão, como bem preceitua o art. 207 da Carta de 1988. Mas, para fins desse estudo, a perspectiva escolhida é a do ensino.

Um dos resultados da prática do ensino nas universidades é a produção de manuais e toda a gama de textos úteis ao estudo de determinada disciplina. Para Bigaton (2012, p. 3), manuais podem ser considerados como:

[...] livros introdutórios e panorâmicos relativos a determinada especialidade, querendo dizer com a primeira predicação que são destinados a pessoas sem conhecimentos previamente adquiridos sobre a matéria versada e com a 
segunda que tratam superficialmente de uma pluralidade de aspectos dessa matéria.

Sobre esses livros introdutórios, Menezes de Almeida (2015, p. 192) diz que:

Muitos deles se apresentam nominalmente como 'cursos' de direito administrativo; outros, via de regra com proposta de maior abrangência, dizem-se 'tratados'; e ainda há os que levam em seus títulos palavras como 'manual', 'ensaio', 'lições', 'princípios', entre outras, ou que simplesmente se intitulam 'direito administrativo', eventualmente adjetivado (por exemplo: 'brasileiro', 'moderno').

Não existem regras claras para definir o que seja cada tipo desses materiais úteis ao estudo de determinada disciplina, que aqui passamos a nomear manuais ou obras. Considerando a diversidade de formas e nomenclaturas, foram levantados manuais produzidos por professores catedráticos, substitutos e extraordinários de Direito Administrativo da Faculdade de Direito de São Paulo e que tratam do tema de maneira introdutória ou genérica. Essa pesquisa no acervo da Biblioteca da Faculdade de Direito da Universidade de São Paulo resultou em um total de sete manuais, listados a seguir.

Tabela 1 - Autores e manuais

\begin{tabular}{|c|c|c|}
\hline Autor & Título & Ano \\
\hline $\begin{array}{c}\text { João Mendes } \\
\text { Júnior }\end{array}$ & $\begin{array}{c}\text { Noções ontológicas de Estado, } \\
\text { soberania, autonomia, federação e } \\
\text { fundação }\end{array}$ & $1960^{3}$ \\
\hline $\begin{array}{c}\text { José Joaquim } \\
\text { Cardozo de } \\
\text { Mello Netto }\end{array}$ & Direito administrativo & 1919 \\
\hline Mario Masagão & Conceito do direito administrativo & 1926 \\
\hline $\begin{array}{c}\text { Spencer Vampré } \\
\text { Repertório geral de jurisprudência, } \\
\text { doutrina e legislação }\end{array}$ & $1925-1927$ \\
\hline Mario Masagão & Direito administrativo & 1936 \\
\hline Mario Masagão & Prelecções de direito administrativo & 1937 \\
\hline Mario Masagão & Direito administrativo & 1938 \\
\hline
\end{tabular}

Fonte: elaboração própria a partir do sistema Dedalus

2 A obra encabeça a tabela pois sua edição original do manual data de 1912. Essa primeira edição não pôde ser localizada e, portanto, adota-se para estudo a 2a edição, de 1960. 
Para atingir o objetivo, a análise se divide em três eixos principais: função dos manuais, temas abordados e fontes utilizadas.

A análise da função de cada manual tem como ponto de partida o viés exegético da teoria do direito administrativo no período republicano, como mostrado por Menezes de Almeida (2015). Ao estudar algumas das obras de direito administrativo produzidas por professores fora do Estado de São Paulo durante a Primeira República, Menezes de Almeida (2015, p. 229) conclui que são obras voltadas à "consolidação dessa ciência, adaptando-a às instituições republicanas". Como consequência, as obras nesse período possuem "viés mais exegético, a reduzir a sua relevância como fontes de teoria do direito administrativo conscientemente produzida", embora também sirvam de base para cursos acadêmicos, na forma de "lições práticas" destinadas a estudantes e profissionais (ALMEIDA, 2015, p. 231-232).

O início dos anos 1940 marca um estágio evolutivo posterior dessa teoria no Brasil, em que estão presentes tanto obras voltadas especificamente ao ensino ou, mesmo sem deixar de fazê-lo, mas mais relacionadas à compreensão do Estado e da administração. Há, ainda, o surgimento de obras que exercem algum papel, direta ou indiretamente, quanto ao exercício dos poderes estatais (ALMEIDA, 2015, p. 249).

Dito isso, a análise da função dos manuais neste artigo procura identificar se essas características se manifestam e em quais nuances no conjunto de manuais da Faculdade de Direito de São Paulo.

O segundo eixo de análise diz respeito aos temas abordados. Menezes de Almeida (2015, p. 235) identifica que, nesse período, o foco temático é direcionado à própria administração. Ele revela a presença de um binômio temático: a organização da administração e ação da administração. São essas, portanto, as duas linhas temáticas principais. Secundariamente, esboça-se também o tema do serviço público, sua noção e o estudo de serviços específicos, como o serviço postal, ferroviário e de defesa (ALMEIDA, 2015, p. 237).

No mesmo sentido, Guandalini Junior (2011) sugere que, com a chegada da República, o discurso administrativista em circulação deixa de focalizar a estruturação e organização da administração e adota, progressivamente, um viés disciplinar. Em outras palavras, surgem temas envolvendo a intervenção da administração na vida dos indivíduos, como poder de polícia ou serviços públicos.

Em momento posterior, na passagem da década de 1930 para 1940 e no período subsequente, Menezes de Almeida (2015, p. 247) observa, no aspecto temático, o aparecimento de obras mais enciclopédicas, que contém muitos capítulos sobre temas variados. São as chamadas "obras em leque". Isso possivelmente ocorre em razão das transformações na estrutura do Estado brasileiro. 
Assim, nesse segundo eixo de análise, procura-se descobrir quais são os temas abordados pelos manuais da Faculdade de São Paulo e, em que medida, eles se aproximam ou se afastam das variantes temáticas acima propostas por Menezes de Almeida (2015) e Guandalini Junior (2011).

Há ainda um terceiro eixo de análise, que diz respeito às fontes doutrinárias mais utilizadas pelos manuais. Essa análise se coloca porque, na teoria do direito administrativo à época, as referências aos antigos autores que ocuparam Cadeira de Direito Administrativo no Império são utilizadas sobretudo em abordagens históricas (ALMEIDA, 2015, p. 233). Assim, aqui se pretende analisar se esse padrão é observando quanto aos autores que escreviam na Faculdade de Direito de São Paulo.

\section{Metodologia}

Como se viu, a análise é tripartite e percorre funções, temas e fontes. Para realizá-la, deve-se estudar os manuais com ênfase na análise dos seus paratextos. Propostos por Genette (2009), os paratextos são a zona de transição entre o texto e tudo que está fora dele. Eles acompanham todo e qualquer texto. Em síntese, paratextos são:

[...] uma zona não apenas de transição, mas também de
transação: lugar privilegiado de uma pragmática e de uma
estratégia, de uma ação sobre o público, a serviço, bem ou
mal compreendido e acabado, de uma melhor acolhida do
texto e de uma leitura mais pertinente [...]. (GENETTE,
2009, p. 10).

Genette (2009) propõe diversas categorias de paratextos. Escolheu-se trabalhar com três delas: o prefácio, os intertítulos e as notas de rodapé.

Prefácio é "espécie de texto liminar (preliminar ou pós-liminar), [...], que consiste em um discurso produzido a propósito do texto que segue ou que antecede" (GENETTE, 2009, p. 145).

Esse texto preliminar nem sempre tem o nome de prefácio. Ele pode ser intitulado também de introdução, prólogo, nota, apresentação, preâmbulo, discurso preliminar, dentre outros. Sua principal função é de "colocar o leitor [...] de posse de informações que o autor julga necessárias a essa boa leitura" (GENETTE, 2009, p. 186).

A análise do prefácio está relacionada ao primeiro eixo de investigação: a função dos manuais. Isso porque o prefácio é o principal elemento que contém fatos sobre a origem daquele escrito, os agradecimentos e os comentários feitos pelo autor, além de revelar as intenções da obra, seu contexto de produção e a escolha de público que foi feita (GENETTE, 2009). 
A eleição dessa categoria para tratar das funções de cada manual tem como inspiração a investigação percorrida por Abreu (2013), acerca do discurso médico presentes nos tratados de medicina luso-brasileiros do século XVIII.

A segunda categoria, intertítulo, é o "título de uma seção do livro: partes, capítulos, parágrafos de um texto unitário, ou poemas, novelas, ensaios constitutivos de uma coletânea". O intertítulo serve de base para o segundo eixo investigativo, uma vez que é nele que estão presentes as indicações do conteúdo a ser percorrido por cada manual (GENETTE, 2009, p. 260).

Por fim, a terceira categoria são as notas. Elas compõem um "enunciado de tamanho variável [...] relativo a um segmento [...] de um texto, e disposto seja em frente seja como referência a esse segmento". A função é de complemento, digressão ou comentário, relacionados a definições de termos, referências de citações, indicação de fontes, dentre outros (GENETTE, 2009, p. 281-288).

As notas são os elementos que guiam a análise do terceiro eixo, focado nas referências feitas pelos manuais aos administrativistas do Império. Para tanto, o conceito de nota não se restringiu às notas de rodapé, mas também foram incluídas as referências textuais que satisfaçam à condição de apresentarem citações e indicações de fontes. Sobre esse tema, explica-se que as citações feitas pelos manuais são reproduzidas aqui somente na medida em que elas auxiliam o argumento. Não se pretendeu reproduzir a integralidade das citações originais, nem exaurir seu conteúdo, pois isso está fora da análise empreendida.

\section{Desenvolvimento}

3.1. Noções ontológicas, de João Mendes Júnior

Uma particularidade do prefácio deste manual é que ele foi elaborado não pelo autor da obra, João Mendes Júnior, mas por um terceiro, que o assina como J. M. N.

Uma possível explicação da autoria do prefácio é a de que ela seja do filho de João Mendes Júnior, João Mendes Neto. Essa hipótese é levantada pelo relato de Alfredo Buzaid (1956). Nele, Buzaid faz referência a outra obra de João Mendes Júnior que, consistindo em uma reunião de artigos publicados pelo mestre, fora reunida e prefaciada por seu filho, João Mendes Neto.

Este manual, editado pela Saraiva no ano de 1960, situa-se décadas após o falecimento de seu autor. Evocando a grandiosidade do autor, o prefácio revela que os textos ali presentes foram extraídos de ensaios escritos por João Mendes Júnior em edições da Revista da Faculdade de Direito de São Paulo.

O histórico de artigos compilados e publicados na forma de livro, com ao menos duas edições, pode ser indicativo de um certo prestígio que se deu a esse manual. 
No caso de o prefaciador ser mesmo João Mendes Neto, a ele é atribuída uma posição privilegiada de falar da obra de seu pai, revelando detalhes quanto à sua gênese da obra, seu conteúdo e revelando até mesmo aspectos biográficos do autor.

Um segundo elemento prefacial é o discurso do Professor Emérito Francisco Morato, de 6 de abril de 1923, na cerimônia de homenagem ao então falecido autor, João Mendes Júnior, nas Arcadas.

Ao que tudo indica, a cerimônia, noticiada pelo Correio Paulistano, contou com a presença do filho de João Mendes Neto. (DR. JOÃO..., 1923, p. 3).

Por isso, talvez seja possível localizar o manual mais próximo das edições em homenagem a um escritor já consagrado, do que daquelas voltadas ao estudo rotineiro dos estudantes. Assim, sua função talvez seja a de consolidar considerações teóricas sobre o direito administrativo, de interesse aos estudiosos. Isso justificaria o esforço de republicar, em nova coletânea, artigos já públicos esparsamente na Revista da Faculdade de Direito, com menção do discurso honroso de Francisco Morato.

Em relação aos temas tratados, aferidos pela análise de intertítulos, é possível perceber que há uma preocupação em definir conceitos pertinentes ao Estado brasileiro em transição, como a ideia de Estado, seu fim, sua ação, sua personalidade, e as noções de autonomia, soberania e federação. Embora enquadrado dentro do binômio organização da administração e ação da administração, o manual se afasta de uma simples explicação sobre a disciplina, abrindo um campo mais amplo de estudos sobre a compreensão do Estado.

Por fim, a análise das notas e citações não mostra nenhuma menção aos antigos administrativistas da Faculdade de Direito de São Paulo. Todavia, é interessante notar que esse manual é citado como doutrina em relação a atos políticos e à distinção de atividade jurídica e atividade social tanto por Mello Netto (1919), quanto por Masagão (1937) o que revela sua importância para a disciplina ao longo do tempo.

\subsection{Direito administrativo, de José Joaquim Cardozo de Mello Netto}

As anotações de aulas que formam esse manual não são antecedidas por nenhum tipo de texto liminar. Elaboradas pelo aluno Manoel Martins Erichsen, da turma de 1906, versam sobre as aulas do professor José Joaquim Cardozo de Mello Netto. Erichsen era aluno da Faculdade de Direito e também do Curso Anexo, tendo sido chamado para a prova escrita de português do curso anexo, segundo Correio Paulistano de 23 de novembro de 1897. Masagão (1926) faz referência a esse compêndio, datando sua produção em 1919.

A organização deste manual indica que não houve um processo de revisão. Ele é formado por diversas preleções, reunidas em conjunto e encadernadas. A separação 
entre uma preleção e outra é feita por meio do uso de um simples sinal tipográfico. Há, ainda, uma indicação de que ele é publicado sem responsabilidade da ilustrada Cadeira.

O nome escrito na página de rosto, “Cazuzianas", é, provavelmente, fruto de uma organização posterior, pois vem escrito na página de rosto a lápis nas cores vermelho e azul, associado a outros comentários ao longo da obra. É também desta forma que aparece o nome de Antonio Paulo da Cunha, advogado da turma de 1920 e que supomos ter sido um dos utilizadores, se não o proprietário do material (MELLO NETTO, 1919).

Nesse aspecto, podemos ver que a sua função está essencialmente ligada aos alunos, que transmitem as ideias do professor em seu lugar. Há, assim, um contexto em que coexistem as lições do professor e anotações de alunos, que são os efetivamente responsáveis pela circulação das ideias do primeiro entre os estudantes.

Quanto aos temas tratados pela obra, por meio da análise dos intertítulos, de modo geral, temos: Conceito e definição de direito administrativo e ciência da administração; Desenvolvimento histórico; Política; Atos políticos e Atos administrativos; Atividade jurídica e atividade social; Funções da administração; Organização da administração; Centralização e descentralização administrativa; Administração dos interesses municipais; Funcionários públicos; Atos administrativos e sua classificação; Responsabilidade do Estado; Funções jurisdicionais da administração; Contencioso administrativo; Conflito de jurisdição e de atribuições; Organização administrativa do Brasil e competências; Contencioso administrativo no Brasil; Ação social do Estado em relação à saúde e instrução e educação do povo. Faz-se aqui presente o binômio organização da administração e ação da administração.

No caso do tema da ação da administração, cabe nota para dizer que apesar de constar como parte integrante do programa de Direito Administrativo, a Ciência da administração não é estudada em sua inteireza:

Na impossibilidade, por falta de tempo, [...] nós nos vamos limitar este anno a dar uma noção a respeito de dois deles [capítulos], os relativos á acção social do Estado na saúde pública e na instrucção e educação do povo. (MELLO NETTO, 1919, p. 235).

Quanto à análise das notas e citações, Ribas, administrativista do Império, foi citado algumas vezes. Primeiramente, como doutrina os temas de distinção entre atos políticos e atos administrativos, como se vê em:

Um dos escriptores que faz mais dinstições entre actos políticos e actos administrativos, sob esse ponto de vista, representando aliás a corrente existente na época, é o Conselheiro Ribas. (MELLO NETTO, 1919, p. 53).

É também mencionado para fazer referência às funções da administração: 
Assim como na vida individual se distinguem a deliberação e a acção, do mesmo modo ellas se discriminam na vida da administração. Na phrase precida do C. Ribas: 'Não é a administração um mechanismo que céga e fatalmente se move ao impulso alheio [...]'. (MELLO NETTO, 1919, p. 106).

Ribas também aparece como referência para o tema de funcionários públicos: "Entre nós, o sr. conselheiro Ribas faz identica distinção. Funccionario publico, para elle, é aquele que exerce uma fracção do poder social [...]" (MELLO NETTO, 1919, p. 151).

E ainda para a classificação de decretos da administração:

Quanto á classificação desta materia, o cons. Ribas divide os decretos em decretos geraes ou regulamentares, e decretos especiaes ou individuaes. (MELLO NETTO, 1919, p. 185).

Outro administrativista imperial, Rubino, é citado como fonte para distinção de atos políticos:

\begin{abstract}
Na prelecção de hoje vamos estudar a doutrina do professor Rubino de Oliveira sobre a materia. Para o professor Rubino, 'quando o Governo procede de um modo geral, temos o acto politico; quando, porém, desce a detalhes, limita-se a individualidades, temos o acto administrativo'. É ahi a mesma noção do conselheiro Ribas, como, por egual, nas seguintes expressões, onde o professor Rubino se contradiz [...]. (MELLO NETTO, 1919, p. 57).
\end{abstract}

\title{
3.3. Conceito do direito administrativo, de Mario Masagão
}

A obra, de 44 páginas, fora editada pelas Escolas Profissionais do Lyceu Coração de Jesus em 1926. Nela, chama atenção uma dedicatória do exemplar ao "Egrégio Mestre" Professor Cardozo de Mello Netto, assinada pelo próprio autor, Mario Masagão, em 12 de março de 1926. A análise do prefácio, intitulado de "Duas Palavras", revela que o objetivo do "folheto", ou também "opúsculo", nas palavras do autor, é contribuir com "ideias úteis a essa obra de sistematização rigorosa" do direito administrativo, a fim de "lhe dar feição de disciplina organizada" (MASAGÃO, 1926, p. 1).

Repleta de sínteses e demonstrações, ela apresenta o desenvolvimento particular das teses de um professor, tendo possivelmente a função principal de desenvolver suas ideias e apresentá-las a outros professores, como o Professor Mello Netto mencionado na dedicatória. 
Apesar disso, não há motivos para esse discurso como ausente dos estudos feitos pelos alunos da Faculdade de Direito. Pelo contrário, o estudo dos outros manuais mostra que Mario Masagão faz referência a essa obra para os seus alunos:

Quanto à divisão da matéria do Direito Administrativo em harmonia com a sua definição acima, pode consultarse o nosso trabalho Conceito do Direito Administrativo, S. Paulo, 1926, pág. 31 e segs. (MASAGÃO, 1959, v. 1, p. 37, grifo do autor).

O conteúdo está dividido, de modo geral, nos seguintes tópicos: Posição do problema; Fins do Estado; Ação jurídica e ação social; Noções relativas ao conteúdo do direito administrativo; Definição de direito administrativo e limites entre este e o direito constitucional; Política e administração; Distribuição do conteúdo do direito administrativo; Elementos estranhos ao direito administrativo; Desapropriação; Responsabilidade civil do Estado; Inadmissibilidade do contencioso administrativo.

Desse conteúdo, vemos que parte se foca em diferenciar o direito administrativo em suas particularidades, por intermédio do estudo da atividade jurídica não contenciosa do Estado, da constituição dos órgãos e também dos meios de ação da administração por atos administrativos. Essa apresentação é bastante similar ao programa da disciplina de 1933 (ANUÁRIO DA FACULDADE DE DIREITO DE SÃO PAULO, 1933), elaborado pelo autor, então catedrático de Direito Administrativo. Por essa razão, a obra em questão talvez tenha servido para estabelecer parâmetros gerais que o autor adotou para o estudo desse ramo do direito quando assumiu a Cadeira.

De todo modo, os temas abordados pela obra não fogem ao biônimo organização da administração e ação da administração.

As citações e notas de rodapé aos antigos administrativistas da Faculdade de Direito de São Paulo são feitas, embora de modo genérico e dentro de uma perspectiva histórica, como vemos em:

Os escritores faziam dela [ciência da administração] a mais extravagante das idéas, considerando-a ora como a filosofia do direito administrativo, ora como o conjunto das doutrinas da administração, passando o direito administrativo a ser apenas o complexo das leis e regulamentos, etc. Semelhantes são os conceitos expressos pelos antigos tratadistas brasileiros, Ribas, Rubino, Uruguái, Rego etc. Era a sciência do tempo. (MASAGÃO, 1926, p. 20).

Notam-se também citações a Cardozo de Mello Netto. Mas, esses casos, do qual o trecho abaixo é apenas exemplificativo, parecem tratar de homenagens feitas por Masagão ao autor, que fora também seu antigo professor e a quem Masagão dedicou um exemplar do manual: 
O ilustre Professor Cardozo de Mello, da Faculdade de São Paulo, repudia, igualmente, o contencioso administrativo, mas aceita a definição de Orlando, sem se lembrar de que esta é feita especialmente para dar guarida áquele monstrengo. Isso nos pareceu uma inadvertência do claro espírito do Prof. Cardozo de Mello, desde quando, nos bancos acadêmicos, lhe ouviamos luminosas lições. (MASAGÃO, 1926, p. 25).

\subsection{Repertório geral de jurisprudência, doutrina e legislação, de Spencer Vampré}

A título de contextualização, façamos um breve comentário sobre o contexto de produção desse manual. A obra de Spencer Vampré se propõe grandiosa, a começar pelo título e pelo tamanho físico. Trata-se de um repertório de doutrina, legislação e jurisprudência extraídos de coleções de arestos, isto é, revistas de jurisprudência e também de publicações oficiais. Não apenas, ela compreende o direito civil, o comercial, o criminal, o constitucional, o administrativo, o judiciário, o internacional público e o internacional privado. Nessa empreitada, o autor intentou escrever sobre sessenta volumes ou assuntos diferentes, cada qual constituindo uma obra em separado, que poderia conter mais de um volume e que seria vendida avulsamente. A título de informação, os preços pareciam variar de $40 \$ 000$ a $105 \$ 000$ réis, como consta dos exemplares.

A função da obra se manifesta, em partes, pela sua monumentalidade editorial. Publicada entre 1925 e 1927, a editoração é feita pela Livraria Acadêmica Saraiva, que nos anos de 1920 já é associada à editoração livros jurídicos em São Paulo (HALLEWELL, 2017). Um dos volumes, no entanto, é editado pela Empreza do Repertorio Geral de Jurisprudencia. Seja qual for a edição, é fato que os volumes possuem muitas páginas e são robustos.

O testemunho da grandeza da edição se revela nos comentários que aparecem no Correio Paulistano. O jornal noticia que o "ilustre publicista" Vampré, com "competencia de um mestre", se dedica a realizar o que é chamado de "vultuoso empreendimento", que está ao "alcance para os advogados, juízes e legisladores". Conclui dizendo que a obra contém "ensinamentos de inegável relevância aos estudiosos de direito". Aqui vemos que a obra não se concentra apenas nos ensinamentos aos alunos, mas também a outros agentes do direito, como advogados, juízes e legisladores. (REPERTORIO..., 1925, p. 7).

Talvez a iniciativa esteja relacionada ao patrocínio do governo português à publicação de alguns livros no Brasil no centenário de sua independência. Isso porque na lombada de alguns volumes lê-se a intitulação "sob o alto patrocínio do governo português", com menção ao despacho ministerial de 12 de maio de 1919, com menção 
ainda a sociedades de "eminentes historiadores e geógrafos" (VAMPRÉ, 1925, v. 1; 1925, v. 3; 1927, v. 4).

A iniciativa parece ter sido tomada por elites de comércio localizadas principalmente no Pará e no Rio de Janeiro, que fomentaram a produção da obra História da Colonização Portuguesa no Brasil (BATALHONE JÚNIOR, 2014), a partir da isenção de impostos sobre papel (ALVES, 2009). Para tanto, foi criada a Sociedade Editora da História da Colonização Portuguesa do Brasil, encarregada exclusivamente da produção da peça literária. Apesar dessas informações, não foi possível encontrar fontes que mostrassem a relação direta entre essa iniciativa e a obra de Vampré. Contudo, mantémse a hipótese, pois um dos volumes é editado pela Empreza do Repertorio Geral de Jurisprudencia, que parece se assemelhar à iniciativa da Sociedade Editoria da História da Colonização Portuguesa do Brasil.

O prefácio, intitulado "Porque se publica este Repertorio", constata uma dicotomia entre a dogmática dos professores da Academia e a prática dos juízes aplicadores da lei. Nele, o manual é um esforço de harmonizar teoria e a prática, revelando a uniformidade dos arestos e sua conformidade com o direito nacional. Mais do que isso, nos é revelado que a gênese da obra é o trabalho de organização da jurisprudência brasileira que durou, ao menos, dez anos. Essa grande pesquisa se volta a "facilitar o trabalho de advogados e juízes" (VAMPRÉ, 1925, v. 1).

Assim, a obra parece se dedicar primordialmente à vida profissional e prática, fato que pode justificar o seu prestígio e, quiçá, tenha garantido os recursos para a grandiosidade de sua publicação.

Nesse sentido, é importante notar as dedicatórias feitas, em alguns volumes, a nomes como Eduardo Espinola, Francisco Morato e Antonio Baptista de Campos Pereira. Os dois primeiros, apesar de terem sido professores, obtiveram bastante reconhecimento na vida profissional, assim como o terceiro.

Apenas um dos volumes, que data de 1927, que faz parte do acervo consultado se refere ao direito administrativo. Ele trata essencialmente do tema da desapropriação, dentro do qual estão, de modo geral, os tópicos: Condições essenciais; Extensão; Laudo; Indenização; Efeitos quanto à locação; Requisições; Processo de desapropriação

A análise dos intertítulos não evidenciou quaisquer referências aos grandes temas da organização da administração e da ação da administração. Tampouco foi possível analisar com propriedade as notas e citações constantes dessa obra, uma vez que as referências estavam inseridas nos trechos de jurisprudência colecionados e, além disso, não citavam nenhum dos administrativistas do Império.

É possível que esse resultado tenha se dado em razão da função da obra, que, nesse caso, é a de compilar jurisprudências sobre o tema da desapropriação. 


\subsection{Direito administrativo, de Mario Masagão}

Este manual não contém nenhum tipo de instância prefacial. Por essa razão é que se passa, desde imediato, à análise dos intertítulos.

O aparato intertitular da obra é rico e nos indica não apenas dos temas abordados, mas também a sua função e seu contexto de produção e circulação.

A obra, na maioria das vezes, constitui-se de um conjunto de folhetins, cada um deles com cinco páginas - exceção feita aos folhetins de número 19, 25 e 52 , quatro, sete e seis páginas respectivamente. A título de detalhamento, vale notar que ela se encontra encadernada no mesmo volume que o manual de 1938 do mesmo autor.

Possivelmente em razão da organização própria desse manual em folhetins, preleções e pontos é que se dá a ausência do nome do professor Mario Masagão no título. Há somente uma anotação manuscrita, em uma das páginas de rosto, que nomeia "Prelecções do professor Mario Masagão na Faculdade de Direito da Universidade de São Paulo". Provavelmente, trata-se de uma anotação posterior, que se refere ao encadernado de dois compilados (1936 e 1938), e não exclusivamente à obra de 1936, visto que a nota está escrita sobre um papel bastante diferente daquele em que os manuais de 1936 e 1938 foram redigidos (MASAGÃO, 1936-1938, p. 1).

A autoria material do texto é referida pela nota ao final "Tachygraphada por", que está presente ao final de cada trecho, junto da indicação "-continua" (MASAGÃO, 1936-1938, p. 5).

Atenção especial seja dada ao uso da expressão "meus senhores". Esse vocativo, que reside na fronteira entre o próprio texto e o seu paratexto, serve para anunciar cada ponto do programa que será exposto na preleção. Por fim, vemos também, ao início de cada folhetim, a expressão "Sem responsabilidade da Illustrada Cadeira" (MASAGÃO, 1936-1938, p. 1).

O taquígrafo do texto de 1936, J. Eduardo Oliveira de Barros, é provavelmente José Eduardo Oliveira de Barros, ora grafado dessa forma e ora como José Eduardo de Oliveira Barros. Seja como for, provavelmente trata-se de José Eduardo Oliveira de Barros, que recebeu diploma de bacharel do Instituto de Tachygraphia, pelo qual obteve nota distintas nos exames - 100 pontos -, segundo notícia do Correio de S. Paulo de 24 de junho de 1933 (INSTITUTO..., 1933). O mesmo, provavelmente, ingressara também na Faculdade de Direito de São Paulo, uma vez que notícia do Correio Paulistano de 11 de dezembro de 1935 publica a sua aprovação em medicina legal (PELAS..., 1935, p. 2). No ano seguinte, em 11 de dezembro de 1936, um tal José Eduardo Oliveira de Barros nota-se a ligeira inversão nos nomes de família - é chamado para exames orais do quinto ano (PELAS..., 1936, p. 13). 
Apesar de sua passagem pela Faculdade, o estudante não consta do registro de bacharéis formados constante do arquivo da Associação de Antigos Alunos da Faculdade de Direito de São Paulo. É noticiado seu falecimento no acidente aéreo de Ponte Nova, pelo Jornal do Brasil em 16 de dezembro de 1939 (O DESASTRE..., 1939, p. 6).

Interessante notar que há folhetins elaborados por outros, como é o caso do 49 , em que consta: "Tachygraphada por Antonio Trippa" e dos folhetins 51 e 52, que não possuem autoria (MASAGÃO, 1936-1938, p. 246).

Sendo assim, podemos ver que se trata de uma obra voltada aos alunos e por eles produzida. Essa constatação ganha peso se considerarmos a importância dos paratextos intertitulares, que remetem à própria dinâmica da sala de aula, onde alunos anotam as explicações e repassam, posteriormente, aos demais. Esses alunos constituem um grupo que se torna responsável pela difusão do conteúdo ministrado pelo professor. Não obstante, é possivelmente por conta disso que os alunos isentam o professor da responsabilidade pelo discurso.

O conteúdo tratado pela obra se apresenta, de modo geral, nos seguintes temas: Noção de direito administrativo e ciência da administração; fins do Estado; Política; Atos administrativos e atos políticos; Desenvolvimento histórico; Funções da administração; Órgãos e suas divisões; Hierarquia e fiscalização; Centralização e descentralização; Funções do Presidente da República; Ministérios; Fiscalização orçamentária; Tribunal de Contas; Necessidade do Conselho de Estado; Administração municipal; Bens públicos; Classificação dos atos administrativos; Polícia administrativa; Contratos; Funcionários e empregados públicos; Serviço público; Concessão; Responsabilidade do Estado; Contencioso administrativo, suas modalidades em vários países e história no Brasil; Conflitos.

Analisando detalhadamente esse assunto, percebemos que a obra inclui uma série de temas, tratados de forma abrangente. Nesse momento, de finais da década de 1930 e início da década de 1940, as obras administrativistas passam a abordar uma série de temas, de um modo enciclopédico ou "em leque" (ALMEIDA, 2015, p. 265-266). Essa característica é aqui evidenciada. Não obstante, é particular o tratamento de alguns temas.

Para além da presença dos temas comuns às obras da primeira fase de consolidação teórica do direito administrativo no Brasil, como noções e história do direito administrativo, organização administrativa, atos administrativos, poder de polícia, serviços públicos, bens públicos e funcionários públicos, existem outros que despertam interesse.

O primeiro deles é o da responsabilidade do Estado, aqui visto como uma espécie de prenúncio de um tema que viria a ser incluído com muito maior intensidade somente nos anos 1950 (ALMEIDA, 2015, p. 265-266). O segundo é a continuidade do 
tema do contencioso administrativo no Brasil, abolido há quase cinco décadas. A obra adota uma perspectiva histórica, centralizada no Brasil, embora não deixe de lado o enfoque teórico e de direito comparado.

Em relação às fontes utilizadas nas notas e citações, é possível ver que a obra menciona Ribas para tratar alguns temas. O primeiro por nós destacado é a distinção entre atos políticos e atos administrativos:

O Conselheiro Ribas, notavel professor de Direito Civil, tambem escreveu um livro a respeito do Direito Administrativo, no qual adoptava aquella classificação [atos políticos e atos administrativos], declarando: 'o poder político tem uma missão’ [...]. (MASAGÃO, 1936-1938, p. $35)$.

A análise das funções da administração também faz jus à menção de Ribas:

O Conselheiro Ribas dividia as funções activas da administração em funcções expontaneas e funcções jurisdicionaes. Funcções expontaneas seriam aquellas em que o Estado opera independentemente de provocação dos administrados, como, por exemplo, uma determinação qualquer generica do poder executivo, por meio de decreto. As funcções jurisdicionaes, dizia o Conselheiro Ribas, podem ser subdividas em graciosas e contenciosas. (MASAGÃO, 1936-1938, p. 46).

Em relação aos funcionários públicos, a menção a Ribas aparece da seguinte

forma:

O nosso RIBAS dizia que funccionario publico exerce uma parcella do poder social, e que os empregados desenpenham certos serviços que têm caracter commum, aos da vida privada, como os trabalhos de escripturação e contabilidade, da guarda, conservação e transporte das coisas publicas, etc. (MASAGÃO, 1936-1938, p. 167).

A obra também menciona Ribas quando intenta classificar decretos da administração:

Os decretos, forma pela qual, em regra, se manifesta a vontade do poder executivo, foram classificados, pelo conselheiro RIBAS, em duas especies: decretos individuaes e decretos regulamentares. Dizia o Conselheiro Ribas que decretos individuais são os que contem providencias attinentes, de maneira especial, a algum individuo, como, por exemplo, o decreto de nomeação de um funccionario publico. Os decretos regulamentares são aquelles em virtude dos quaes o governo faz baixar regulamento, para bôa execução da lei. (MASAGÃO, 1936-1938, p. 121). 
Outro administrativista da Faculdade de Direito de São Paulo à época do Império e que aparece nas explicações de Masagão é Rubino. Quanto a ele, faz-se menção ao seu conceito de atos administrativos:

\begin{abstract}
No mesmo caminho do Conselheiro Ribas tinhamos o Conselheiro Rubino, tambem notavel professor, que distinguia actos politicos e actos administrativos do Poder Executivo, e dizia que, quando o governo procede de um geral, pratica um acto politico; e quando desce á particularidades, pratica actos administrativos. (MASAGÃO, 1936-1938, p. 36).
\end{abstract}

\title{
3.6. Prelecções de direito administrativo, de Mario Masagão
}

O manual em questão, intitulado "Prelecções", é também uma coleção de folhetins que contém a anotação das aulas feitas pelos alunos. Dentro dos folhetins, estão as preleções - aulas - propriamente ditas, de modo que cada folhetim contém o final preleção escrita no folhetim anterior e começo de uma nova preleção. Neste caso, as aulas foram proferidas por Mario Masagão e os folhetins possuem quatro páginas cada (MASAGÃO, 1937).

Nele, existem dois textos prefaciais. O que aparece primeiro é uma simples nota, sem título, atribuindo a autoria à aluna taquígrafa Iete Ribeiro de Souza, e ao aluno E. C. Fraga, que orientou a impressão.

O segundo texto, que aparece depois do primeiro, data de abril de 1937. Ele contém um importante registro sobre a prática desse tipo de material na Faculdade de Direito de São Paulo.

Os textos liminares foram escritos, ao que tudo indica, pelos mesmos alunos responsáveis pela taquigrafia. Sobre eles, levantou-se que Iete Bomilcar Ribeiro de Souza foi aluna da Faculdade de Direito da turma de 1938. A preleção em questão foi elaborada com auxílio de E. C. Fraga, provavelmente Egberto Campos Fraga, da turma de 1939, segundo consta no arquivo da Associação de Antigos Alunos.

Egberto Campos Fraga também auxiliou a impressão de Prelecções de Direito Civil, do professor Lino de Moraes Leme, de Direito Civil. Esta, taquigrafada por Lupercio Marques de Assis, da turma de 1938, apresenta algumas diferenças na encadernação. No entanto, a sua página de rosto é bastante semelhante. Ambas foram impressas pela mesma gráfica e possuem o mesmo texto prefacial. Assim, é provável que alguns alunos estavam envolvidos na produção de mais de um manual desse tipo durante o ano letivo.

Apesar de não serem os próprios alunos os responsáveis pela autoria intelectual da obra, eles assumem o prefácio como verdadeiros autores, procurando 
incentivar a leitura do texto, revelando a sua importância, a sua urgência e mostrando a unidade de um texto que, a princípio, é divido. Há, ainda, uma autocrítica, em que os alunos pedem complacência pelos eventuais erros de impressão.

O prefácio deixa claro que a função desempenhada pela obra é acadêmica. Todavia, ele também pode sugerir que o discurso está em disputa entre o professor e os próprios alunos. Se, de um lado, a autoria intelectual das ideias pertence ao professor, de outro a forma de divulgação desse conteúdo é dada a um grupo de alunos. A importância desse grupo é evidenciada pela própria organização da atividade de taquigrafar a aula e do comércio das anotações, o que forma um verdadeiro manual.

O fato de que nas páginas de rosto e ao longo da obra vemos a inscrição manuscrita ou carimbada - do nome de Fernando Henrique Mendes de Almeida, que foi o antigo dono do material, segundo os registros da Biblioteca da Faculdade de Direito, e aluno da turma de 1936, evidencia a destinação do material aos alunos.

Em razão de seu formato de organização próprio em folhetins, os intertítulos, também fornecem muitas informações sobre a produção do manual. Pôde-se constatar que toda preleção se inicia pela expressão "meus senhores". No topo de todas as páginas, vemos um perene, que marca "5ªnno" (MASAGÃO, 1937, p. 1).

A análise do conteúdo dos intertítulos revela o tratamento dos seguintes temas: Noção de direito administrativo e ciência da administração; Fins do Estado; Atividade jurídica e atividade social; Política; Atos administrativos e atos políticos; Desenvolvimento histórico; Funções da administração; Órgãos e suas divisões; Hierarquia e fiscalização; Centralização e descentralização; Funções do Presidente da República; Ministérios; Fiscalização orçamentária; Tribunal de Contas; Necessidade do Conselho de Estado; Administração municipal; Bens públicos; Polícia administrativa; Contratos; Funcionários e empregados públicos. Todos eles refletem a noção de Menezes de Almeida (2015, p. 265-266) de que, no final da década de 1930, passam a abundar obras que tratam de diversos temas de direito administrativo, de modo enciclopédico ou obras "em leque". Todavia, na comparação com Direito Administrativo, 1936, do mesmo autor, nota-se a ausência na obra mais recente de referências aos temas do serviço público, da história do contencioso administrativo e da responsabilidade do Estado. Esses assuntos podem ter sidos preteridos por inúmeras razões, como, por exemplo, a falta de tempo para ministrar todo o conteúdo da disciplina naquele ano em específico. O que vale notar é que esses três temas constam do programa da disciplina elaborado por Masagão, em 1933, (ANUÁRIO DA FACULDADE DE DIREITO DE SÃO PAULO, 1933).

Quanto às notas e citações, novamente Ribas surge como doutrina os temas de distinção entre atos políticos e atos administrativos:

O Conselheiro Ribas, como consequencia da distinção erronea que fazia, chegava a admittir que o poder executivo 
ficava divido em dois ramos [...]. (MASAGÃO, 1937, p. 68).

Também para o tema de funções da administração:

'Espontaneas', dizia Ribas, são as funcções exercidas, pela administração publica, independentemente de provocação por parte do administrado [...]. (MASAGÃO, 1937, p. 76).

E igualmente no caso de decretos da administração: "O Conselheiro Ribas, por exemplo, declarava que os decretos se dividiam em duas especies [...]" (MASAGÃO, 1937, p. 149). E, ainda, como doutrina para o tema de funcionários públicos:

O conselheiro Ribas, entre nós, procurava enquadrar-se nessa corrente. Declarava elle que os empregados publicos exercem funcções correspondentes a alguns empregos da vida civil ou commercial [...]. (MASAGÃO, 1937, p. 194).

Quanto a Rubino, mais uma vez é também citado como referência para definição de atos políticos

O professor Rubino, ao fazer distincção substancialmente identica á de Ribas, dizia que [...]. (MASAGÃO, 1937, p. 68).

\subsection{Direito administrativo, de Mario Masagão}

O manual de 1938, como vimos, encontra-se encadernado com a obra de 1936. São sete folhetins de cinco páginas cada. O manual, apesar de começar no folhetim de número um, é possível que seja uma continuação. A sua leitura indica que a exposição do assunto já havia sido há muito iniciada e, temporalmente, o fragmento corresponde aos meses de setembro e outubro de 1938.

Como visto, o autor intelectual é identificado pela anotação da página de rosto. Quanto aos autores materiais, consta, ao final, a nota "Taqui: - J.G.J". Não há texto prefacial. São os intertítulos que indicam a função da obra, seu contexto de produção e circulação e os temas por ela abordados. Ao início de cada folhetim, há a data, a disciplina e o vocativo "meus senhores" (MASAGÃO, 1936-1938, p. 35).

O discurso é produzido por alunos com base nas preleções em sala de aula, contendo características marcantes presentes no intertítulo, como interrupções e informações referenciais para situar o leitor a cada novo folhetim. O manual é destinado aos alunos, que, como visto, assumem a responsabilidade pelas ideias. Há, novamente, algum tipo de apropriação do discurso do professor.

A análise do conteúdo dos intertítulos resta prejudicada, pois, segundo o que se verificou, a obra é apenas um fragmento do que poderia ter sido um compêndio 
em sua totalidade. De qualquer forma, os temas tratados nessa restrita parte são: Serviços públicos; Concessão de serviço público; Responsabilidade do Estado decorrente de atos dos funcionários da administração. A partir disso, e comparando essa obra com as demais, pode-se supor que ela talvez tenha se proposto tratar vários temas, em uma abordagem “em leque”, como aponta Menezes de Almeida (2015, p. 265-266). Porém, não é possível dizer com certeza.

Pelos mesmos motivos já apontados, a análise das notas de rodapé e citações também não revelou informações.

\section{Conclusão}

As conclusões da pesquisa dividem-se nos três eixos temáticos de análise que percorremos ao longo deste artigo, que são: i) função das obras; ii) temas abordados pelas obras; e iii) citações feitas pelas obras aos administrativistas da Faculdade de Direito de São Paulo no período imperial.

Em relação à função das obras, verificada pela análise dos prefácios, as considerações de Menezes de Almeida (2015) parecem se aplicar também para o grupo de professores da Faculdade de Direito de São Paulo.

Os professores da Faculdade de Direito de São Paulo, em harmonia com a teoria administrativista de outros locais, no período de 1889 a 1940 escrevem, no mais das vezes, obras acadêmicas voltadas aos alunos. A forma exegética de desenvolvimento da teoria nesse período, como fora apontado por Menezes de Almeida (2015), está possivelmente relacionada à presença de materiais produzidos pelos próprios alunos, que é o caso de quatro manuais analisados: Mello Netto (1919) e Masagão (1936, 1937, 1938).

Um caso interessante é o de Repertório Geral, de Vampré (1925, v. 1; 1925 , v. $3 ; 1926$, v. $2 ; 1926$, v. 2, t. 2; 1927, v. 4). Essa obra situa-se entre os bancos da academia e o meio profissional. Tomando forma de uma coleção de jurisprudência sobre desapropriação, a obra enfatiza o viés prático do direito administrativo, que, longe de estar restrito aos alunos, era também e talvez até mais dirigido aos operadores do direito.

No entanto, fugindo à função de explicações acadêmicas ou profissionais, aparecem duas obras: Noções de Estado, Autonomia, Federação e Fundação, de João Mendes Júnior (1912, cuja reedição de 1960 foi por nós abordada) e Conceito do Direito Administrativo, de Masagão (1926).

Quanto à primeira, parece que se está diante de uma obra voltada à compreensão do Estado e da administração, motivada pela transição entre os regimes ocorrida em 1889. Essa característica evidencia se nos lembrarmos de que a sua segunda edição data de 1960, momento em que a teoria do direito administrativo já deixara de ser exegética e explicativa e começam a surgir livros mediatos, que desempenham papel de 
reflexão, crítica ou suporte quanto ao exercício dos poderes estatais (ALMEIDA, 2015). Ainda sobre ela, o prefácio e o contexto de produção da segunda edição revelam o prestígio que recai sobre o autor: o memorável João Mendes Júnior. Talvez em função disso é que a obra, original de 1912, continua a ser citada pelos professores da disciplina em 1919 e em 1937. Isso mais interessante considerando o tempo de cerca de um ano e meio, que João Mendes Júnior, como substituto, dedicou à disciplina de Direito Administrativo, no período de 1909 a 1916.

Quanto à segunda obra, de Masagão, parece estar relacionada ao desenvolvimento de ideias sobre a disciplina de Direito Administrativo, não inteiramente apartado do ambiente acadêmico. Pelo contrário, na comparação com o programa de Direito Administrativo de 1932 (ANUÁRIO DA FACULDADE DE DIREITO DE SÃO PAULO, 1932), elaborado pelo mesmo autor, notam-se semelhanças. Não obstante, a obra traz ainda um diálogo próximo com Cardozo de Mello Netto, que antecedeu Masagão no Cadeira da disciplina.

O segundo eixo de análise é dos temas abordados pelas obras, verificados por estudo dos intertítulos. Para tanto, recordemo-nos de que, em um primeiro momento, que vai do Império até o período republicano, a teoria do direito administrativo no Brasil estava em formação. Segundo Menezes de Almeida (2015), mais precisamente no período da Primeira República, a estruturação temática das obras ocorre em função da centralidade da administração, cujo estudo é um binômio, divido em dois grandes temas. O primeiro deles é a organização da administração. O segundo grande tema do binômio é a ação da administração. Essa constatação fora também trazida por Guandalini Junior (2011), que identificou, no começo do período republicano, uma tendência do discurso administrativo à abordagem de temas disciplinares, com influência mais direta na vida dos cidadãos, como é o caso do poder de polícia e dos serviços públicos.

Ainda trazendo Menezes de Almeida (2015), essa fase da teoria administrativa na Primeira República foi gradualmente transformada para chegar, em começo dos anos 1940, a um primeiro estágio de constituição teórica. Esse momento propicia o aparecimento de obras cuja abordagem é enciclopédica ou em leque. São obras mais abertas e que tratam de vários temas, com alguns pontos em comum.

Essas considerações de pertinência temática se verificaram para a maioria dos manuais da Faculdade de Direito de São Paulo.

No caso das obras do início da Primeira República, o foco é a organização e a ação da administração, mesmo que o binômio sofra modulações de acordo com cada autor e obra.

No tocante à obra de João Mendes (1960), o recorte é centralizado nas noções de autonomia, federação e na atuação do Estado face às fundações. Perspectiva 
semelhante é seguida por Masagão (1926), cujas explicações também recaem sobre a organização da administração.

Diferentemente coloca-se Vampré (1926, v. 2, t. 2). O autor escolhe, na obra em questão, analisar um tema específico - a desapropriação. Embora seja por ele considerado como parte da ação da administração, o tema parece controverso, pois, anos depois, vem a ser excluído do estudo do direito administrativo por Mario Masagão.

No período, parece que Cardozo de Mello Netto (1919) é o único a abordar o binômio organização e ação da administração de modo a destrinchar a maior parte do seu conteúdo.

Ao final dos anos 1930, encontramos as obras de Masagão (1936, 1937, 1938), que apresentam um número maior de temas abordados. Dentre esses, merece destaque os temas de serviço público, de concessões, de poder de polícia e de bens, que ganham força progressivamente. Ao mesmo tempo, nelas vai se deixando de lado temas que eram outrora estudados, como o da jurisdição administrativa - ainda que esse estudo parecia ser, desde anos anteriores, apenas uma contextualização histórica. Disso, concluise que são obras mais distantes do binômio organização e ação da administração e mais próximas de uma abordagem em leque dos temas do direito administrativo.

Vale notar que a presença constante de determinados temas na Faculdade de Direito possivelmente seja também resultado da adoção dos programas individuais de cada professor que rege a Cadeira. Porém, de modo geral, parece que esses programas refletiam, em alguma medida, o que se discutia sobre a teoria administrativista no restante do país.

Por fim, analisaram-se as notas e citações a fim de identificar como possíveis fontes a doutrina dos administrativistas que atuaram na Faculdade de Direito de São Paulo durante o Império.

Essa análise não teve a pretensão de identificar uma teoria regional ou de determinada instituição sobre o direito administrativo. A formação de uma teoria se estende ao longo do tempo, não se constituindo de um fenômeno isolado. Tampouco se propôs a avaliar eventual formação de uma continuidade teórica - tendo em questão a continuidade teórica do fenômeno inicial para a formação da teoria e que, no campo do direito administrativo, ocorre somente em meados de 1940

O olhar, nesse eixo, voltou-se à procura de eventuais marcas de abordagem e regularidade de temas que constituem padrões de referências em comum. Tais padrões referenciais podem ser aceitos, discutidos ou, até mesmo, negados. O mais relevante é que eles propiciam o diálogo das obras de uma geração com aquelas das gerações posteriores.

$\mathrm{O}$ resultado mostra que o pertencimento à Faculdade de Direito de São Paulo parece justificar a presença, em alguma medida, nos autores estudados, de alguns padrões de referências comuns em relação a temas específicos. O caso mais emblemático 
é o do Conselheiro Ribas, referenciado nas obras de Cardozo de Mello Netto (1919) e Masagão (1936, 1937) como doutrina para os temas: distinção entre atos políticos e atos administrativos, funções da administração; funcionários públicos e classificação de decretos da administração.

O mesmo ocorre com Rubino, também citado em Cardozo de Mello Netto (1919) e Masagão $(1936,1937)$ para a definição de atos políticos da administração.

Todavia, as referências não foram encontradas em quatro obras: a de João Mendes Júnior (1960) e as de Mario Masagão (1926, 1938) e a de Vampré (1926, v. 2, t. 2). Possivelmente, isso acontece, no caso das duas primeiras, por se tratarem as obras não de simples explicações e apontamentos, mas de obras mais relacionadas à compreensão geral do Estado e da administração. No caso de Direito Administrativo de Masagão (1938), a falta de citações talvez se dê porque se trata, na verdade, da parte final de algo que possivelmente se perdeu ao longo do tempo, como evidenciou a análise do material.

No caso de Vampré (1926, v. 2, t. 2), a ausência de referência talvez seja fruto da especificidade da função da obra. Vampré nela não se vale de referências, salvo aquelas contidas nas decisões compiladas.

Ainda que não tenha sido possível identificar uma base referencial comum e válida para todas as obras, é certo dizer que ela aparece nas obras mais voltadas aos alunos da academia. Isso pode apontar tanto para preferências pessoais dos professores que ministravam as aulas, quanto para possíveis tradições existentes no ambiente de ensino. Seja como for, está colocado, em alguma medida, um diálogo dos autores republicanos com os imperiais e, menos explicitamente, desses com as novas gerações de estudantes da faculdade.

São Paulo, abril de 2020

\section{Referências}

ABREU, Jean Luiz Neves. Tratados e construção do saber médico: alguns aspectos dos paratextos nos impressos de medicina luso-brasileiros - século XVIII. Revista Territórios e Fronteiras, Cuiabá, v. 6, n. 2, p. 21-34, jul./dez. 2013.

ALMEIDA JÚNIOR, João Mendes de. Elementos de lógica e de psicologia: uma sinopse da história da filosofia. 2. ed. São Paulo: Saraiva, 1963.

ALMEIDA JÚNIOR, João Mendes de. Noções ontológicas de estado, soberania, autonomia, federação e fundação. São Paulo: Saraiva, 1960. 
ALMEIDA JUNIOR, João Mendes de; MAIA, Julio Joaquim Gonçalves; CASTILHOS, Honorio de. Relatorio: Faculdade de Direito de São Paulo, 8 de janeiro de 1913. Revista da Faculdade de Direito de São Paulo, São Paulo, v. 20, p. 343-364, jan./dez. 1912. Disponível em: http://www. revistas.usp.br/rfdsp/article/view/65155/67766.

ALMEIDA, Fernando Dias Menezes de. Formação da teoria do direito administrativo no Brasil. São Paulo: Quartier Latin, 2015.

ALVES, Jorge Luís dos Santos. Malheiro Dias e o luso-brasileirismo: um estudo de caso das relações culturais Brasil - Portugal. 2009. Tese (Doutorado) - Instituto de Filosofia e Ciências Humanas, Universidade do Estado do Rio de Janeiro, Rio de Janeiro, 2009.

ANUÁRIO DA FACULDADE DE DIREITO DE SÃO PAULO. São Paulo: Empresa Gráfica da Revista dos Tribunais, 1932.

ANUÁRIO DA FACULDADE DE DIREITO DE SÃO PAULO. São Paulo: Empresa Gráfica da Revista dos Tribunais, 1933.

BARROS JÚNIOR, Carlos S. de. Antonio Joaquim Ribas: o conselheiro Ribas. Revista da Faculdade de Direito da Universidade de São Paulo, São Paulo, v. 69, n. 2, p. 239-253, jan./dez. 1974.

BATALHONE JÚNIOR, Vitor Claret. A "História Pátria" entre dois monumentos: o passado colonial nas notas de rodapé da História geral do Brasil e da História da colonização portuguesa no Brasil. Revista de História, São Paulo, n. 170, p. 317-342, jan./jun. 2014.

BIGATON, Lucas Haddad. Manuais de direito administrativo no Império do Brasil: autores, propostas e fontes. 2012. Conclusão de Curso (Graduação em Direito) - Faculdade de Direito, Universidade de São Paulo, São Paulo, 2012.

BUENO, Antonio Dino da Costa. Relatorio da Faculdade de Direito de S. Paulo, 2 de janeiro de 1909. Revista da Faculdade de Direito de São Paulo, São Paulo, v. 16, p. 179-205, jan./dez. 1908. Disponível em: http://www.revistas.usp.br/rfdsp/article/view/65087/67698.

BUENO, Antonio Dino da Costa. Relatorio da Faculdade de Direito de São Paulo pelo diretor Antonio Dino da Costa Bueno. Revista da Faculdade de Direito de São Paulo, São Paulo, v. 17, p. 261-283, jan./dez. 1909. Disponível em: http://www.revistas.usp.br/rfdsp/article/view/65096/67707.

BUENO, Antonio Dino da Costa. Relatorio: Faculdade de Direito de São Paulo, 21 de janeiro de 1911. Revista da Faculdade de Direito de São Paulo, São Paulo, v. 18, p. 217-236, jan./dez. 1910. Disponível em: http://www.revistas.usp.br/rfdsp/article/view/65111/67722.

BUENO, Antonio Dino da Costa. Relatorio: Faculdade de Direito de S. Paulo, 2 de janeiro de 1912. Revista da Faculdade de Direito de São Paulo, São Paulo, v. 19, p. 371-422, jan./dez. 1911. Disponível em: http://www.revistas.usp.br/rfdsp/article/view/65137/67748.

BUZAID, Alfredo. João Mendes de Almeida Jr.: aspectos de uma grande vida. Revista da Faculdade de Direito da Universidade de São Paulo, São Paulo, v. 51, p. 73-97, jan./dez. 1956. 
CARVAlHO, Antonio Amancio Pereira de. Relatorio do anno de 1918. Revista da Faculdade de Direito de São Paulo, São Paulo, v. 22, p. 355-368, 1914-1925a. Disponível em: http://www. revistas.usp.br/rfdsp/article/view/65189/67794.

CARVAlHO, Antonio Amancio Pereira de. Relatorio do anno de 1919. Revista da Faculdade de Direito de São Paulo, São Paulo, v. 22, p. 369-385, 1914-1925b. Disponível em: http://www. revistas.usp.br/rfdsp/article/view/65190/67795.

DR. JOÃO Mendes: homenagens á memoria do saudoso mestre: missa em suffragio da sua alma: sessão cívica solene na Faculdade de Direito: os discursos. Correio Paulistano, São Paulo, n. 21.459, p. 3, 6 abr. 1923. Disponível em: http://memoria.bn.br/pdf/090972/per090972_1923_21459.pdf.

EXAMES de preparatorios. Correio Paulistano, São Paulo, n. 12.365, p. 4, 23 nov. 1897. Disponível em: http://memoria.bn.br/pdf/090972/per090972_1897_12365.pdf.

FERRAZ, Antonio Januario Pinto. Relatorio relativo ao anno de 1928. Revista da Faculdade de Direito de São Paulo, São Paulo, v. 25, p. 403-415, 1929. Disponível em: http://www.revistas.usp. $\mathrm{br} / \mathrm{rfdsp} / \mathrm{article} / \mathrm{view} / 65251 / 67856$.

FERRAZ, Antonio Januario Pinto. Relatorio relativo ao anno lectivo de 1926. Revista da Faculdade de Direito de São Paulo, São Paulo, v. 23, p. 339-351, 1927. Disponível em: http://www.revistas. usp.br/rfdsp/article/view/65214/67819.

FERRAZ, Antonio Januario Pinto. Relatorio relativo ao anno lectivo de 1927. Revista da Faculdade de Direito de São Paulo, São Paulo, v. 24, p. 433-446, 1928. Disponível em: http:/www.revistas. usp.br/rfdsp/article/view/65230/67835.

FREITAS, Vicente Mamede de. Relatorio da Faculdade de Direito de S. Paulo pelo diretor Vicente Mamede de Freitas. Revista da Faculdade de Direito de São Paulo, São Paulo, v. 15, p. 153-179, jan./dez. 1907. Disponível em: http://www.revistas.usp.br/rfdsp/article/view/65075/67686.

FREITAS, Vicente Mamede de. Relatorio. Revista da Faculdade de Direito de São Paulo, São Paulo, v. 14, p. 203-229, jan./dez. 1906. Disponível em: http://www.revistas.usp.br/rfdsp/article/ view/65066/67677.

FREITAS. Uladislau Herculano de. Relatorio do anno de 1914. Revista da Faculdade de Direito de São Paulo, São Paulo, v. 22, p. 291-306, 1914-1925a. Disponível em: http://www.revistas.usp.br/ rfdsp/article/view/65185/67790.

FREITAS. Uladislau Herculano de. Relatorio do anno de 1915. Revista da Faculdade de Direito de São Paulo, São Paulo, v. 22, p. 307-326, 1914-1925b. Disponível em: http://www.revistas.usp.br/ rfdsp/article/view/65186/67791.

FREITAS. Uladislau Herculano de. Relatorio do anno de 1916. Revista da Faculdade de Direito de São Paulo, São Paulo, v. 22, p. 327-337, 1914-1925c. Disponível em: http://www.revistas.usp.br/ rfdsp/article/view/65187/67792. 
FREITAS. Uladislau Herculano de. Relatorio do anno de 1917. Revista da Faculdade de Direito de São Paulo, São Paulo, v. 22, p. 339-354, 1914-1925d. Disponível em: http://www.revistas.usp.br/ rfdsp/article/view/65188/67793.

FREITAS. Uladislau Herculano de. Relatorio do anno de 1920. Revista da Faculdade de Direito de São Paulo, São Paulo, v. 22, p. 387-401, 1914-1925e. Disponível em: http://www.revistas.usp.br/ rfdsp/article/view/65191/67796.

FREITAS. Uladislau Herculano de. Relatorio do anno de 1921. Revista da Faculdade de Direito de São Paulo, São Paulo, v. 22, p. 403-312, 1914-1925f. Disponível em: http://www.revistas.usp.br/ rfdsp/article/view/65192/67797.

FREITAS. Uladislau Herculano de. Relatorio do anno de 1922. Revista da Faculdade de Direito de São Paulo, São Paulo, v. 22, p. 413-431, 1914-1925g. Disponível em: http://www.revistas.usp.br/ rfdsp/article/view/65193/67798.

FREITAS. Uladislau Herculano de. Relatorio do anno de 1923. Revista da Faculdade de Direito de São Paulo, São Paulo, v. 22, p. 433-440, 1914-1925h. Disponível em: http://www.revistas.usp.br/ rfdsp/article/view/65194/67799.

FREITAS. Uladislau Herculano de. Relatorio do anno de 1924. Revista da Faculdade de Direito de São Paulo, São Paulo, v. 22, p. 441-447, 1914-1925i. Disponível em: http://www.revistas.usp.br/ rfdsp/article/view/65195/67800.

FREITAS. Uladislau Herculano de. Relatorio do anno de 1925. Revista da Faculdade de Direito de São Paulo, São Paulo, v. 22, p. 449-460, 1914-1925j. Disponível em: http://www.revistas.usp.br/ rfdsp/article/view/65196/67801.

GENETTE, Gérard. Paratextos editoriais. Tradução de Álvaro Faleiros. Cotia: Ateliê Editorial, 2009.

GUANDALINI JUNIOR, Walter. Gênese do direito administrativo brasileiro: formação, conteúdo e função da ciência do direito administrativo durante a construção do Estado no Brasil Imperial. 2011. Tese (Doutorado em Direito) - Faculdade de Direito. Universidade Federal do Paraná, Curitiba, 2011.

HALLEWELL, Laurence. O livro no Brasil: sua história. 3. ed., I reimpr. São Paulo: EDUSP, 2017.

INSTITUTO de tachygraphia. Correio de S.Paulo, São Paulo, anno 2, n. 319, p. 2, 24 jun. 1933. Disponível em: http://memoria.bn.br/DocReader/docreader.aspx?bib=720216\&pasta=ano\%20 193\&pesq=Jos\%C3\%A9\%20Eduardo\%20Oliveira\%20de\%20Barros\&pagfis=1890.

MACHADO,Antonio de Alcantara. Relatorio referente ao ano de 1931, apresentado ao excêlentissimo Senhor Diretor Geral de Educação, pelo Dr. Alcantara Machado, diretor da Faculdade de Direito de São Paulo. Revista da Faculdade de Direito de São Paulo, São Paulo, v. 28, p. 151-169, 1932. Disponível em: http://www.revistas.usp.br/rfdsp/article/view/65308/67913. 
MASAGÃO, Mário. Conceito do direito administrativo. São Paulo: Escolas Profissionaes do Lyceu Coração de Jesus, 1926.

MASAGÃO, Mário. Curso de direito administrativo. São Paulo: Max Limonad, 1959. v. 1.

MASAGÃO, Mário. Curso de direito administrativo. São Paulo: Max Limonad, 1960. v. 2.

MASAGÃO, Mário. Direito administrativo. São Paulo: [s.n.], [entre 1936 e 1938].

MASAGÃO, Mário. Preleç̧ões de direito administrativo. São Paulo: Faculdade de Direito da Universidade de São Paulo, 1937.

MELLO NETTO, José Joaquim Cardozo de. Direito administrativo. São Paulo: [s. n.], 1919.

O DESASTRE de aviação ocorrido em Ponte Nova: realizaram-se, hontem, em S. Paulo, entre manifestações de pesar, os funerais dos Drs. Alvaro Girão e Oliveira de Barros e do piloto Cesar Falcão. O corpo do Major Ferraz Filho chegará hoje à capital. Jornal do Brasil, Rio de Janeiro, ano 49, n. 297, p. 6, 16 dez. 1939. Disponível em: http://memoria.bn.br/DocReader/ docreader.aspx?bib=030015_05\&pasta $=$ ano $\% 20193 \&$ pesq $=\% 22$ desastre $\% 20 \mathrm{de} \% 20$ avia\%C3\%A7\%C3\%A3o\%20de\%20ponte\%20nova\%22\&pagfis=97905.

PELAS escolas: Faculdade de Direito. Correio Paulistano, São Paulo, n. 24.456, p. 2, 11 dez. 1935. Disponível em: http://memoria.bn.br/pdf/090972/per090972_1935_24456.pdf.

PELAS escolas: Faculdade de Direito. Correio Paulistano, São Paulo, n. 24.768, p. 13, 11 dez. 1936. Disponível em: http://memoria.bn.br/pdf/090972/per090972_1936_24768.pdf.

\section{PROGRAMMAS DA FACULDADE DE DIREITO DE SÃO PAULO ADOPTADOS NO ANNO}

DE 1931. São Paulo: Typ. Siqueira, 1931.

REPERTORIO geral de jurisprudência, doutrina e legislação. Correio Paulistano, São Paulo, n. 22.100, 4 fev. 1925. Secção Judiciaria, p. 7. Disponível em: http://memoria.bn.br/pdf/090972/ per090972_1925_22100.pdf.

VAMPRÉ, Spencer. Repertório geral de jurisprudência: doutrina e legislação; comprehendendo o direito civil, commercial, criminal, constitucional, administrativo, judiciario, e internacional publico e privado, e extrahido das mais reputadas coleções de aréstos. São Paulo: Saraiva, 1925. v.

1: Do agravo e da carta testemunhável.

VAMPRÉ, Spencer. Repertório geral de jurisprudência: doutrina e legislação; comprehendendo o direito civil, commercial, criminal, constitucional, administrativo, judiciario, e internacional publico e privado, e extrahido das mais reputadas coleções de aréstos. São Paulo: Saraiva, 1926. v. 2: Dos embargos.

VAMPRÉ, Spencer. Repertório geral de jurisprudência: doutrina e legislação; comprehendendo o direito civil, commercial, criminal, constitucional, administrativo, judiciario, e internacional publico e privado, e extrahido das mais reputadas coleções de aréstos. São Paulo: Saraiva, 1926. v. 2, t. 2: Da prova civil, commercial, administrativa e criminal. 
VAMPRÉ, Spencer. Repertório geral de jurisprudência: doutrina e legislação; comprehendendo o direito civil, commercial, criminal, constitucional, administrativo, judiciario, e internacional publico e privado, e extrahido das mais reputadas coleções de aréstos. São Paulo: Saraiva, 1925. v. 3: Da appellação civil e criminal.

VAMPRÉ, Spencer. Repertório geral de jurisprudência: doutrina e legislação; comprehendendo o direito civil, commercial, criminal, constitucional, administrativo, judiciario, e internacional publico e privado, e extrahido das mais reputadas coleções de aréstos. São Paulo: Saraiva, 1927. v. 4: Das provas em direito commercial, administrativo e criminal. 